\title{
Effects of 28 days of two creatine nitrate based dietary supplements on bench press power in recreationally active males
}

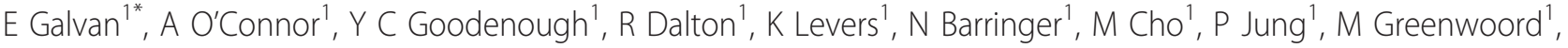 \\ C Rasmussen ${ }^{1}$, PS Murano ${ }^{2}$, C P Earnest ${ }^{1,3}$, R Kreider $^{1}$
}

From The Twelfth International Society of Sports Nutrition (ISSN) Conference and Expo

Austin, TX, USA. 11-13 June 2015

\section{Background}

Athletes use ergogenic aids in an attempt to increase training-adaptations, which serves to enhance their performance during competition. Creatine monohydrate is one of the most studied ergogenic aids. Although many studies have reported the efficacy and effectiveness of creatine monohydrate supplement manufacturers continually introduce newer forms of creatine into the marketplace. The newer forms of creatine purport to be more effective than creatine monohydrate alone. However, there is little evidence to support most manufacturers' claims.

\section{Methods}

We examined $28 \mathrm{~d}$ of randomly assigned (1) placebo (PL), (2) Creatine monohydrate (CrM; 3 g), (3) creatine nitrate (CrN; $1 \mathrm{~g} \mathrm{CrM}$; $0.5 \mathrm{~g} \mathrm{~N}$ ) and (4) CrN2X (2 g CrM; 1.0 g N) on bench press performance. Participants $(\mathrm{N}=48$; $21 \pm 3$ yrs) presented for fasting $(12 \mathrm{~h})$ testing after abstaining from exercise and alcohol for $48 \mathrm{~h}$. Performance (reps at $70 \%$ of bench press $1 \mathrm{RM}$ ) was measured using a Tendo Fitrodyne at $0 \& 28 \mathrm{~d}$ and analyzed by MANOVA or one-way ANOVA. Mean changes $(95 \% \mathrm{CI})$ were reported.

\section{Results}

We previously reported (FASEB J, 29(1):LB248, 2015) that all treatment groups increased bench press repetitions after $28 \mathrm{~d}$ of supplementation; however, total work (reps $\times$ weight lifted) during bench press was greater at $28 \mathrm{~d}$ for CrN2X (294.6 lbs; 95\% CI, 196, 393) vs. CrN (164.2 lbs;

\footnotetext{
* Correspondence: egalvan@hlkn.tamu.edu

'Exercise \& Sport Nutrition Lab, Texas A\&M University, College Station, TX, USA

Full list of author information is available at the end of the article
}

95\% CI, 25, 304) and PL (187.1 lbs; 95\% CI, 37, 336, both $\mathrm{p}=0.02)$. MANOVA univariate analysis of power data indicated a significant time effect with all power output variables (i.e., peak power (PP), average power (AP), and average velocity (AV)). No significant group by time effects were observed among groups. One-way ANOVA of the $3^{\text {rd }}$ set of exercise performed to exhaustion revealed no significant differences among groups in changes from baseline after $28 \mathrm{~d}$ of supplementation. However, pairwise comparison of $95 \%$ CIs revealed a significant difference in peak power and average power between CrN2X (522.8 W; 95\% CI, 473.5, 572.2) and PL $(422.9 \mathrm{~W} ; 95 \% \mathrm{CI}, 386.6$, 499.1, $\mathrm{p}=0.037)$ and CrN2X (470.3 W; 95\% CI 422.1, 518.5) and PL (386.1 W; 95\% CI, 331.1, 441.0, $\mathrm{p}=0.025$ ), respectively. Average power was also significantly different between CrN2X $(470.3 \mathrm{~W}$; 95\% CI 422.1, 518.5) and $\mathrm{CrN}$ (384.0 W; 95\% CI, 335.8, 432.2, $\mathrm{p}=0.014$ ). Average velocity during bench press test was also significantly different between $\mathrm{CrN}(0.629 \mathrm{~m} / \mathrm{s} ; 95 \% \mathrm{CI}, 0.572,0.686)$ and $\mathrm{PL}$ $(0.525 \mathrm{~m} / \mathrm{s} ; 95 \%, 0.460,0.590, \mathrm{p}=0.02)$.

\section{Conclusion}

Results suggest some ergogenic value of consuming these types of creatine containing pre-workout supplements on bench press power adaptations during training in comparison to PL responses.

\section{Acknowledgements \\ Supported by Nutrabolt, Corp (Bryan, TX).}

\section{Authors' details}

${ }^{1}$ Exercise \& Sport Nutrition Lab, Texas A\&M University, College Station, TX, USA. ${ }^{2}$ Institute for Obesity and Program Evaluation, Texas A\&M University, College Station, TX, USA. ${ }^{3}$ Research \& Development, Nutrabolt Corp., Bryan, TX, USA. 
- Convenient online submission

- Thorough peer review

- No space constraints or color figure charges

- Immediate publication on acceptance

- Inclusion in PubMed, CAS, Scopus and Google Scholar

- Research which is freely available for redistribution 